\section{Analysis of Young Infant Deaths Using Verbal Autopsies: Clarifications Needed}

We compliment the authors on their work on verbal autopsies for infant deaths [1]. We seek the following clarifications:

i) The study mentions about a State verbal autopsy tool, but no details of it could be found either in the text or the references.

ii) We want to know source of individual death information, which was crucial for timely execution of verbal autopsy tool. What was number and qualification of the field workers? There is no mention of parental consent before collecting the information.

iii) Authors mention that clinical summaries of babies were collected from health posts near their residence. Were they public/private hospitals/clinics? What if they refused to provide confidential data to field workers? Even if they had access to individual case sheets of all babies who died, how did they interpret it in the absence of a pediatrician on site?

iv) The study mentions an infant mortality rate of 5.2 per 1000 live births, which is much below the national average. Kindly elaborate.

v) Discussion section mentions about the 108 neonatal ambulance service, but the number 108 is for general ambulance and 102 is the number for dedicated maternal and neonatal/infantile services.

Shahid AKhtar Siddiqui* and Mukesh Vir Singh Department of Pediatrics, SN Children Hospital, MLN Medical College, Prayagraj, Uttar Pradesh. *sha.akht@yahoo.com

\section{REFERENCE}

1. Devi RU, Bharathi SM, Kumutha J. Analysis of young infant deaths using verbal autopsies and accuracy of verbal autopsy tool in Chennai, India. Indian Pediatr. 2021;58:363-66.

\section{AUTHORS' REPLY}

We thank the readers for their interest in our article [1], and provide the desired information:

i) The contents of verbal autopsy form are available at $h t t p s: / /$ nhm.gov.in/images/pdf/programmes/childhealth/ guidelines/Operational_Guidelines_Child_Death_ Review.pdf and have been modified in the Tamil Nadu State verbal autopsy form to include health seeking behavior, each cause of death based on symptoms or problems in the child. The State verbal autopsy tool has maternal characteristics as well as neonatal characteristics. For neonatal deaths as well as post neonatal deaths, there are set of questions under each cause of deaths and depending upon the answers, one of the major causes is selected. Probable main cause of death (only one cause) is to be given at the end.

ii) All young infant deaths ( $<2$ months) between March, 2013 and March, 2015 were line-listed as per government orders. Investigation of the same was done using the State verbal autopsy forms for infant deaths. Line-listing of young infant deaths is routinely done by field workers assigned in each Chennai corporation zone, and it was not done solely for the purpose of the study. Investigation of these deaths are done using verbal autopsy forms after getting informed consent from the parents by the field workers (auxiliary nursing midwives, ANM), also called as urban health nurse in urban area. These health workers had finished the ANM course and had undergone a two-week training on verbal autopsy.

iii) Permission for procuring line listing as well as verbal autopsy questionnaires from all zones of Chennai Corporation for the purpose of our study was obtained from the Deputy Project coordinator, district family welfare, Chennai Corporation. Babies having residence within Chennai Corporation zones and who died within 2 months of age between April, 2013 and March, 2015 were included in the study.

Deaths that occurred at home and private hospitals were also line-listed and included. Case sheets of those collected and scrutinized before the district level verbal audit of infant deaths (government, private, home deaths) done bi-monthly and the physician who treated the baby also attends the audit. The case sheet details and clinical diagnoses of deaths in private setup were noted by us for the study. In case of home deaths, diagnosis as given at arrival to hospital or in the death certificate was taken.

iv) We have provided the "young" infant ( $<2$ months) mortality rate in the article and not the infant mortality rate. Total live births among the residents of Chennai corporation zones were 164009 , out of which there were 865 young infant deaths.

v) Regarding transport, 108 ambulance service is utilized for neonatal services as well in Tamil Nadu, with the calls requesting for neonatal services getting filtered and channelized separately.

Mangala Bharathi S, * Usha DeVi R Department of Neonatology, Institute of Child Health and Hospital for Children, Madras Medical College, Chennai, Tamil Nadu. *drmangalabharathi@gmail.com

\section{REFERENCE}

1. Devi RU, Bharathi SM, Kumutha J. Analysis of young infant deaths using verbal autopsies and accuracy of verbal autopsy tool in Chennai, India. Indian Pediatr. 2021;58:363-66. 